F. Reprod. Fert. (1966) 12, 365-368

BRIEF COMMUNICATION

\title{
FREE AMINO ACIDS IN THE SEMEN OF THE FOWL AND THE TURKEY*
}

\author{
B. S. AHLUWALIA $†$ AND E. F. GRAHAM \\ Department of Dairy Husbandry, University of Minnesota, \\ St Paul, Minnesota
}

(Received 22nd November 1965, revised 4th March 1966)

\begin{abstract}
Summary. A total of eighteen amino acids were determined quantitatively in the seminal plasma and spermatozoa of fowl semen. Glutamic acid was the major component in both fractions. In the spermatozoan fraction, only six amino acids were detected, namely glutamic acid, lysine, arginine, serine, aspartic acid and threonine. Except for serine and lysine, the amino acid concentrations in the spermatozoan fraction were much smaller than in the seminal plasma. In general, the amino acid content of turkey seminal plasma is similar to chicken seminal plasma with a few quantitative differences.
\end{abstract}

A detailed, quantitative analysis of free amino acids in fowl seminal plasma and spermatozoa and turkey seminal plasma has not been reported previously. Amino acids prolong the functional life of Echinoderm spermatozoa probably by acting as chelating agents in the semen or in the diluents (Hayashi, 1945; Metz, 1945; Runnström, Monne \& Wicklund, 1946; Tyler \& Atkinson, 1950; Wicklund \& Gustafson, 1949). Glycine and glutamate (El Zayat \& Van Tienhoven, 1961) were found to depress the respiration rate. Glycine and some egg proteins (Lorenz \& Tyler, 1951) have been shown to extend markedly the motile life-span of fowl spermatozoa.

Semen was collected twice a week from thirty male birds of mixed breed, by a modified technique of Burrows \& Quinn (1937), pooled and frozen to $-20^{\circ} \mathrm{C}$ until a total of $25 \mathrm{ml}$ was obtained. At the time of analysis the samples were thawed and centrifuged at $5000 \mathrm{~g}$ for $20 \mathrm{~min}$ in a refrigerated centrifuge. The seminal plasma and the spermatozoan fractions were immediately separated and examined under the microscope. The spermatozoan fraction was washed twice with double-distilled water and centrifuged each time to remove any extraneous material adhering to the cell walls. The washed spermatozoan fraction was then resuspended in $25 \mathrm{ml}$ of double-distilled water, thoroughly mixed and transferred to the Raytheon Oscillator, Model S102A, and subjected to ultrasonic vibration for approximately $12 \mathrm{hr}$ to break the cell membranes.

* Paper No. 5328 Scientific Journal Series, Minnesota Agricultural Experiment Station.

$\uparrow$ Research Fellow, The Hormel Institute, University of Minnesota, Austin, Minnesota. 
Analyses of amino acids were conducted on the spermatozoan fraction and seminal plasma.

For comparative studies analyses were also conducted using the same techniques on the seminal plasma of turkey semen pooled from twenty-five birds.

Determinations of the amino acids were carried out in the Spinco-Automatic Recording Amino Acid Analyser Model 120 as described by the manufacturer for physiological fluids. Ion exchange columns of sulphonated polystyrene resin (Spackman, Stein \& Moore, 1958; Stein, 1953; Stein \& Moore, 1954) are employed in this instrument for the separation of amino acids. The samples, before analysis, were de-proteinized with five times the volume of $1 \%$ solution

\section{TABLE 1}

COMPARISON OF THE CONTENT (MG/100 ML) OF ACIDIC, NEUTRAL AND BASIC AMINO AGIDS AND OTHER NON-PROTEIN NITROGENOUS SUBSTANCES IN FOWL AND TURKEY SEMEN

\begin{tabular}{l|c|c|c}
\hline & $\begin{array}{c}\text { Pooled chicken } \\
\text { seminal plasma }\end{array}$ & $\begin{array}{c}\text { Sperm cell } \\
\text { portion of pooled } \\
\text { chicken semen }\end{array}$ & $\begin{array}{c}\text { Pooled turkey } \\
\text { seminal plasma }\end{array}$ \\
\cline { 2 - 3 } & $11 \cdot 0$ & Absent & $15 \cdot 3$ \\
Asparagine & $3 \cdot 1$ & $4 \cdot 0$ & $12 \cdot 9$ \\
Aspartic acid & $4 \cdot 1$ & Trace & $6 \cdot 9$ \\
Alanine & $9 \cdot 7$ & Trace & Absent \\
Glycine & $1178 \cdot 00$ & $192 \cdot 5$ & $956 \cdot 3$ \\
Glutamic & $2 \cdot 0$ & $6 \cdot 0$ & $18 \cdot 0$ \\
Serine & $5 \cdot 2$ & Absent & Absent \\
Taurine & $11 \cdot 0$ & $2 \cdot 1$ & $6 \cdot 6$ \\
Threonine & $3 \cdot 1$ & Trace & $4 \cdot 0$ \\
Valine & $18 \cdot 5$ & $10 \cdot 7$ & $27 \cdot 6$ \\
Arginine & $3 \cdot 4$ & Absent & Absent \\
Histidine & Trace* & Absent & Trace \\
Isoleucine & $3 \cdot 4$ & Trace & $4 \cdot 6$ \\
Leucine & $2 \cdot 4$ & $12 \cdot 8$ & $2 \cdot 1$ \\
Lysine & $10 \cdot 8$ & Trace & $1 \cdot 5$ \\
Methionine & Trace & Absent & Absent \\
Tryptophan & $5 \cdot 3$ & Trace & $5 \cdot 5$ \\
Tyrosine & Trace & Trace & $2 \cdot 5$ \\
Ornithine & Absent & Absent & Absent \\
Phenylalanine & $3 \cdot 2$ & $15 \cdot 8$ & Absent \\
Ammonia & Trace & $1 \cdot 1$ & Trace \\
Ethanolamine & Trace & Absent & Absent \\
Urea & $29 \cdot 4$ & & \\
\hline & &
\end{tabular}

of picric acid. The resulting precipitate was then removed by centrifugation for $15 \mathrm{~min}$ at $5000 \mathrm{~g}$, and excess picric acid was removed with a $2 \times 20 \mathrm{~cm}$ column of Dowex 2-X10 in the chloride form. The walls of the chromatographic column and resin bed were washed with five $3 \mathrm{ml}$ portions of 0.02 $\mathrm{N}-\mathrm{HCl}$. The sample was then transferred to a $5 \mathrm{ml}$ volumetric flask and made up to a volume using buffer $\mathrm{pH} 2 \cdot 2$. A $2 \mathrm{ml}$ aliquot of this solution was pipetted on each of the two columns of the Spinco-Analyser.

Table 1 shows that glutamic acid is the major component in the chicken seminal plasma comprising almost $92 \%$ of the total amino acids present. In addition, arginine, threonine, methionine, asparagine and glycine were present 
in large quantities, whereas tyrosine, taurine, alanine, leucine, valine, histidine, aspartic acid, lysine and serine were present in smaller amounts. Isoleucine, tryptophan and ornithine were present only in trace quantities.

The analysis of the amino acids of the spermatozoan fraction (Table 1) suggests that only a few amino acids are present in more than trace amounts. Glutamic acid was the major component and accounts for about $84 \%$ of the total free amino acids. Lysine and arginine are also present in large amounts, whereas serine, aspartic acid and threonine are present in much smaller quantities.

The amino acid analysis of the turkey seminal plasma indicated qualitatively the same picture as for fowl seminal plasma except that glycine, taurine and histidine were absent. Urea was surprisingly not detectable in turkey seminal plasma, whereas in chicken seminal plasma it was a major component. The absence of urea in the spermatozoan fraction of chicken semen was expected because it was washed several times.

The results shown in Table 1 indicate that glutamic acid is the predominant amino acid in semen; it is present in amounts over $1 \mathrm{~g} / 100 \mathrm{ml}$ in seminal plasma. This has been reported by several workers. Our results are in general agreement with the qualitative data reported by Chubb \& Cooper (1962) on fowl seminal plasma. However, some of the amino acid and ninhydrin-reacting substances, e.g. cysteic acid, cystine, glutamine and citrulline, which these workers identified by paper chromatography, were not found in our investigation. Perhaps these substances were present in our samples in too small amounts to be detected as discrete peaks. The analysis of the spermatozoan portion indicated that only six major amino acids, glutamic acid, lysine, arginine, serine, aspartic acid and threonine, were present. The others were present only in trace amounts or absent. Serine and lysine were present in higher quantities, and glutamic acid, arginine and threonine were present in much smaller quantities in the spermatozoan fraction of chicken semen than in the seminal plasma. This might suggest that there is selective permeability of amino acids from extracellular to intracellular spaces; the lesser quantities of some amino acids present inside the spermatozoa may be due to rapid metabolism of these amino acids as soon as they enter the cell.

We are grateful to Dr I. E. Liener and Dr Carl Graves of the Department of Biochemistry for their kind help in preparation of the communication.

\section{REFERENCES}

Burrows, W. H. \& Quins, J. P. (1937) The collection of spermotazoa from domestic fowl and turkeys. Poult. Sci. 16, 19.

Chubb, L. G. \& Cooper, M. D. (1962) Amino acids in fowl seminal plasma. J. Reprod. Fert. $4,7$.

EL Zayat, S. \& VAn Trenhoven, A. (1961) Effect of glutamate and glycine on cock sperm metabolism. Proc. Soc. exp. Biol. Med. 106, 803.

HAYASH, T. (1945) Dilution medium and survival of the spermatozoa of Arbacia punctulata. I. Effect of the medium on fertilizing power. Biol. Bull. mar. Biol. Lab., Woods Hole, 89, 162.

Lorenz, F. W. \& Tyler, A. (1951) Extension of motile life span of spermatozoa of the domestic fowl by amino acids and proteins. Proc. Soc. exp. Biol. Med. 78, 57. 
METz, C. B. (1945) The agglutination of starfish sperm by fertilizin. Biol. Bull. mar. Biol. Lab., Woods Hole, 89, 84.

Runnström, J., Monne, L. \& Wigklund, E. (1946) Studies on the surface layers and the formation of the fertilization membrane in sea urchin eggs. F. Colloid Sci. 1, 421.

Spackman, D. H., Stein, W. H. \& Moore, S. (1958) Automatic recording apparatus for use in the chromatography of amino acids. Analyt. Chem. 30, 1190.

SrEIN, W. H. (1953) A chromatographic investigation of amino acid constituents of normal urine. 7. biol. Chem. 201, 45.

Stein, W. H. \& Moore, S. (1954) The free amino acid of human blood plasma. F. biol. Chem. 211, 915.

Tyler, A. \& Atkinson, E. (1950) Prolongation of the fertilizing capacity of sea urchin spermatozoa by amino acids. Science, N.Y. 112, 783.

Wicklund, E. \& Gustafson, T. (1949) The effect of glycine on the membrane formation in the eggs of sea urchin Strongylocentrotus droebockiensis. Ark. Zool. 42A, 1. 